\title{
Time Dependent Effect of the Combination of Transcranial Direct Current Stimulation and Transcutaneous Electrical Nerve Stimulation in Knee Osteoarthritis Patients
}

\author{
Rekha Chaturvedi*(a), Shabnam Joshi(b)
}

a) Assistant Professor, Guru Jambheshwar University of Science and Technology, Hisar, Haryana. Contact number 7206322394, Email: rekhachaturvedi85@gmail.com.

b) Associate Professor, Guru Jambheshwar University of Science and Technology, Hisar, Haryana. Contact number 9729922466, E mail: shabnamphysio@gmail.com.

\begin{abstract}
Background: Osteoarthritis is a highly prevalent musculoskeletal condition. A huge variety of treatment interventions are available but have shown success to limited extent. Treatment intervention managing the symptoms both at the periphery and at the central pain processing can be a better approach to the treat this condition. Objective: The present study aimed to see the time effect of the combination of Transcranial direct current stimulation (tDCS) and Transcutaneous electrical nerve stimulation (TENS) in knee OA patients. Study design: Pre- post experimental study design. Methodology: Seventeen patients with chronic knee osteoarthritis as per American College of Rheumatology criteria were recruited in the study. The combination of tDCS and TENS was applied for 5 consecutive days over the most painful knee. The outcome measures were pain (VAS), function (six minute walk test), disability and quality of life (Knee injury and osteoarthritis outcome score) measured at the baseline, one week, two weeks and six weeks after the interventions. Data was analyzed using SPSS (version 21.0) software. Result: The result of the study showed significant improvement in pain, function and quality of life at the short term (week 1) as well as in long term (6 weeks) after the interventions. Conclusion: The combination of tDCS and TENS is a potential intervention in reducing pain and improving function both at short and long term in knee OA patients.
\end{abstract}

Key words: Pain management, Knee osteoarthritis, Transcranial direct current stimulation, Therepeutic effect 


\section{Introduction}

Osteoarthritis (OA) is amongst the most common rheumatic musculoskeletal disorders which is highly prevalent and is imposing an enormous financial burden to the society along with the physical and psychological outcomes [1]. According to Global burden of disease study 2017, it is estimated that 303 million people are affected by osteoarthritis globally [2]. A huge variety of pharmacological and non pharmacological treatments are available to treat this condition [3, 4]. However, these treatment approaches have shown benefit to a limited extent in these patients. Earlier, the pain in osteoarthritis was considered as peripheral model of pain generated by the structural damage at the joint. However, various studies have shown inconsistencies in the extent of damage in the radiographs with the pain and have shown inter individual variability in the severity of pain with the structural damage depicting some other mechanism to be responsible for pain in OA patients $[5,6,7,8]$. The recent studies have proposed two mechanisms for pain in OA patients which are peripheral sensitization and central sensitization [9, 10, 11] Substantial scientific evidences indicate the role for central sensitization in OA [10, 11, 12, 13, 14]. Various studies supporting the phenomenon of central sensitization in OA have displayed that the repetitive nociceptive inputs generated from peripheral joint receptors are transmitted to dorsal horn neurons in the spinal cord and this repetitive and intense nociceptive inputs is responsible for central sensitization in OA patients [15]. Therefore, interventions that can modulate these nociceptive inputs at the central level can be seen as a potential approach to treat this condition. The non invasive brain stimulation techniques have gained popularity in treating various conditions which involves central sensitization by altering the central pain processing systems in the body. Transcranial direct current stimulation (tDCS) is a potent noninvasive brain stimulation intervention that has gained significant attention in treating chronic pain conditions because of its neuromodulatory effect [16, 17, 18, 19]. The application of tDCS involves applying low amplitude direct current stimulation on the scalp via surface electrodes. The application of these currents causes change in the polarity of the membrane underneath the electrodes and to the area distant to the electrode bringing the changes in the excitability of the cerebral cortex. The effect of the tDCS is dependent on the area of stimulation, polarity, intensity and number of sessions. The anodal stimulation increases the cortical excitability whereas, the cathodal stimulation is seen to decrease the cortical excitability. Nowadays the effects of tDCS have been explored in variety of conditions such as fibromyalgia, chronic low back pain, stroke, multiple sclerosis, phantom limb pain and traumatic spinal cord injury. Lefaucheur et al. 2017 compiled the use of tDCS in chronic pain conditions such as spinal cord injury, peripheral neuropathy, chronic low back pain, fibromyalgia, myofascial pain, plantar fasciitis, migraine, trigeminal neuralgia, low back pain, abdominal or pelvic pain, postoperative pain, phantom limb pain, multiple sclerosis and arthralgia and have suggested that anodal stimulation over primary motor cortex (M1) may reduce pain by modulating the neural circuits in the precentral gyrus involving the sensory component of the pain processing system or by facilitating descending pain inhibitory controls [20,21]. The pain management by the application of transcutaneous electrical nerve stimulation (TENS) in knee OA patients is a conventional approach. Application of low amplitude currents by tDCS induces changes in the neuronal membrane potential and releases endogenous opioids in the mid anterior cingulate cortex and periaqueductal gray matter [22,23]. Application of high-frequency TENS, manages pain by segmental inhibition in the pain gate along with descending pain suppression via the opioid mechanisms. Thus, the cortical effects produced by tDCS and the spinal and peripheral effects obtained by TENS can be a competent approach to manage this condition appropriately. Various studies have suggested that the effect of tDCS is dependent on the site, polarity, number of sessions and duration of stimulation [24, 25]. Thus, the time dependent effect of tDCS in KOA patients can also be explored. A study has explored the longitudinal effect of tDCS in knee OA patients via functional infrared spectroscopy and showed significant increase in the levels of oxyhemoglobin- and deoxyhemoglobin-related functional activations with the application of tDCS suggesting increase in cortical excitability along with the decrease in pain with its neuromodulatory effect on the cortical pain processing [26]. Keeping in view of the potential neuromodulatory effect of tDCS, the present study aims to find out the time dependent effect of the combination of tDCS with TENS in knee OA patients hypothesizing that the combination of the interventions may produce better treatment outcomes and can improve the clinical and mechanistic effects in knee OA patients.

\section{Methodology}

For this study 17 patients were recruited ( 6 male, 12 female, with the mean age $54.88 \pm 6.78$, height $128.92 \pm 6.47$, weight $72.75 \pm 9.13$ and BMI $28.87 \pm 3.74$ ) with uni/ bilateral knee affected from the community. The patients were selected on the basis of inclusion and exclusion criteria. The inclusion criteria for the study was based on the criteria 
laid by the American College of Rheumatology (ACR) that includes the presence of knee pain and any three of the following symptoms i) Age over 45 years ii) Morning stiffness lasting less than 30 min iii) Crepitus iv) Bony tenderness v) Bony enlargement vi) No palpable warmth [27]. The exclusion criteria for the study includes i) Any knee surgery in the past 6 months ii) Knee joint replacement or high tibial osteotomy on the affected side iii) Other muscular, joint or neurological conditions affecting the functions of the lower limb iv) Unable to walk unaided v) Currently undertaking any exercise program for knee OA vi) Contraindications to tDCS (eg, epilepsy).

\section{Procedure}

The participants were screened and selected based on the inclusion and exclusion criteria. The selected participants were given the combination of tDCS and TENS for 5 consecutive days. The application of tDCS involves applying low amplitude direct current over the scalp via the surface electrodes. For application of tDCS the anode was placed on C3-C4 areas of the cerebral cortex (as per EEG electroencephalogram system) contralateral to the affected knee and cathode over the supraorbital area ipsilateral to the affected knee. For tDCS stimulation current intensity of 2 $\mathrm{mA}$ for 20 min was given. TENS was applied over the medial and lateral side of the most painful knee and a frequency of $100 \mathrm{~Hz}$ for 20 min was applied. Both the equipments were turned on and off simultaneously. All the participants were given hot packs and isometrics of quadriceps and hamstrings of 10 repetitions for 3 sets and supervised exercise sessions after the interventions for next 5 weeks. The intake of any medication was noted at the baseline. The subjects were asked to continue medication, if any during the participation in the trial.

\section{Ethical consideration}

The present study was approved by the Institutional Ethics Committee (IEC) and followed ethical standards for human participants declared in Helsinki, 2013. The study is prospectively registered under clinical trial registry with number CTRI/2018/02/012027 in February 2018.

\section{Data Analysis}

The data was reported in mean and standard deviation. The data was analyzed using repeated measure ANOVA at significance level $5 \%$, multiple corrections using bonferroni correction was used to evaluate the effect of combination of tDCS and TENS on outcome measures in knee OA patients.

\section{Outcome measures}

Pain: Clinical pain was assessed by using visual analogue scale (VAS) which is a subjective scale for pain on a 10 cm scale. Left end indicates 0 means 'no pain' and right end indicates 10 means 'extreme pain'. The patient was asked to mark a point to indicate the pain. Minimal clinically important difference (MCID) ranged from 1.2-2.0 on 10 -point scale [28, 29].

Function: The function was measured using six minute walk test (6MWT) for assessment of function. Six minute walk test involves walking in a corridor of 30 min with cones placed at the start and end of the distance. The participant was asked to walk at own pace and the time was noted in a stop watch and the total distance covered in six minute was measured at the end of six minute. Six-minute walk test is a reliable tool for objective measurement of function in knee osteoarthritis [30]. MCID ranged from 14.0-30.5m [31] with 24.5m after exercise training [32, 33].

\section{Disability:}

The disability was measured using Knee osteoarthritis outcome score (KOOS) questionnaire which is an extension of WOMAC and contains symptoms, pain, function, sports and recreation, quality of life components. The score ranges from 0 to 100 where 100 indicate minimum problem. KOOS is a reliable assessment tool in Indian knee OA patients [34]. MCID for pain, symptom, function, sports and quality of life (QoL) component of KOOS were 7.9, 1.2, 8.1, 21.7 and 27.3 respectively [35]. The assessment of the outcome variables was done on baseline (i.e day 0, prior to the first session of tDCS and TENS), week 1, 2 and at week 6. To estimate the immediate effect of the intervention on pain the value for pain was also assessed immediately after the application of intervention.

\section{Result}

A total of 28 patients were screened for participation in the study. Out of these 20 were recruited for the study. 8 participants were excluded following the inclusion and exclusion criteria. 5 participants declined to participate,2 participant were involved in other structured program for knee OA and 1 participant was contraindicated to 
application of tDCS. Out of 20 participants, data obtained from 17 patients were used to analyze the result. 3 participants dropped out from the study and 1 showed mild symptom of dizziness after the application of the interventions and 1 participant had history of fall at home so, was unable to continue the treatment.

The result of the study showed a significant reduction in pain just after the application of intervention showing the immediate effect of the intervention. The reduction in pain was significant at the week 1 and at week 2 . The effect of the interventions remained consistent at week 6 . The effect size for pain was found to be large. The reduction in pain was clinically significant and was higher than the MCID value for pain [28, 29].

Functional improvement measured by six minute walk test showed significant improvement at week 2 and was maintained at week 6 . The effect size for functional improvement measured by six minute walk test was 0.73 . The improvement was also found to be clinically significant $[35,36]$. The other disability and quality of life measured by KOOS showed significant improvement in KOOS symptom, pain, function, sports function and quality of life sub variables at week 1, 2 and at week 6 showing the short and long term effect of the interventions in patients with knee OA. The effect size for KOOS symptom subvariable was 0.90 , pain 0.77 , function 0.86 , sports function 0.73 and quality of life 0.89 . The KOOS symptom, pain and function sub variable were found to be clinically significant [35]. Table 1 showing within and between subject differences for the participants of the study.

\section{Discussion}

This study aimed to see the short and long term effect of tDCS and TENS in knee OA patients and the result of the study showed that the combination of tDCS and TENS is effective in pain reduction at immediate, short and long term after the treatment. However, the functional improvement measured by six minute walk test was significant at week 2. The functional improvement was also found to be significant at week 6 following the interventions. The disability and quality of life measured by KOOS showed significant improvement in all the KOOS subvariables of symptoms, pain, function, sports function and quality of life at week 1, 2 and 6 showing the short and long term effect of the interventions. The reduction in pain can be because of the modulation of pain via "top down bottom up mechanism" i.e top down is modulating pain at the cortex and bottom up is modulating the pain gate mechanism through segmental inhibition at the periphery, or can be because of the priming effect of the intervention. The priming effect is increasing the effect of the subsequent intervention. Schabrun et al. 2014 used tDCS along with the peripheral electrical stimulation and showed significant reduction in pain chronic low back pain in patients of patients via "Top down botton up" mechanism [36]. The priming effect of tDCS on pain is explored by various researchers in a variety of conditions such as chronic neurogenic pain, chronic low back pain and stroke .Boggio et al. 2009 used anodal tDCS in combination with TENS and has shown 36\% reduction in pain with the combined application of tDCS and TENS as compared to the isolated application in chronic neurogenic pain patients [37]. Hazime et al. 2015 used tDCS in combination with peripheral electrical stimulation and showed significant reduction in pain in chronic low back pain patients [38]. Jafarzadeh et al. 2017 used tDCS in combination with the postural training in chronic low back pain patients and showed significant reduction in pain and improvements in the balance and stability [39]. Luedtke et al. 2015 used anodal tDCS along with the cognitive behavioural therapy and has shown no significant reduction in pain and disability in patients of chronic low back pain patients [40]. Whereas, Straudi et al.2018 used tDCS along with the group exercises in chronic low back pain patients and has shown significant reduction in pain [41]. To our knowledge, only three studies have explored the effect of tDCS in knee OA till date and have reported significant improvement in pain and function [42-44]. Therefore, it can be suggested from the finding of the study that the combination of tDCS and TENS is an effective intervention to improve the pain and function both, at the short and long term in knee OA patients. Thus, can be seen as an potential approach for treating knee OA patients. Randomized controlled trials with large number of patients with long follow up can be undertaken to further explore the findings of the study in order to generalize the result in knee OA patients.

\section{Conclusion}

The combination of tDCS and TENS is a potential approach to manage pain and improve function in knee OA patients.

Acknowledgement: A very special acknowledgement to late Dr. Kulandaivelan S., my former guide who will always be remembered for his unconditional support and guidance.

Conflict of Interest: The authors declare no conflict of interest between the authors.

\section{References}


1. Litwic A, Edwards MH, Dennison EM, Cooper C. Epidemiology and burden of osteoarthritis. Br Med Bull. 2013; 105:185-199. doi:10.1093/bmb/lds038.

2. GBD 2017 Disease and Injury Incidence and Prevalence Collaborators. Global, regional, and national incidence, prevalence, and years lived with disability for 354 diseases and injuries for 195 countries and territories, 1990-2017: a systematic analysis for the Global Burden of Disease Study 2017. Lancet. 2018 Nov 10;392(10159):1789-1858. doi: 10.1016/S0140-6736(18)32279-7. Epub 2018 Nov 8. Erratum in: Lancet. 2019 Jun 22; 393(10190):e44. PMID: 30496104; PMCID: PMC6227754.

3. Ferreira RM, Torres RT, Duarte JA, Gonçalves RS. Non-Pharmacological and Non-Surgical Interventions for Knee Osteoarthritis: A Systematic Review and Meta-Analysis. Acta Reumatol Port. 2019 Jul 29;44(3):173-217. English. PMID: 31356585.

4. Joshi S, Singh SK, Vij JS. Effect of retrowalking, a non-pharmacological treatment on pain, disability, balance and gait in knee osteoarthritis: a randomized controlled trial. Indian Journal of Public Health Research \& Development 2019;10:214-9.

5. Bedson J, Croft PR. The discordance between clinical and radiographic knee osteoarthritis: a systematic search and summary of the literature. BMC Musculoskelet Disord. 2008;9:116.

6. Conaghan PG, Felson DT. Structural associations of osteoarthritis pain: lessons from magnetic resonance imaging. Novartis Found Symp. 2004;260:191- 201.

7. Felson DT, Chaisson CE, Hill CL, et al. The association of bone marrow lesions with pain in knee osteoarthritis. Ann Intern Med. 2001;134:541-549.

8. Hill CL, Hunter DJ, Niu J, et al. Synovitis detected on magnetic resonance imaging and its relation to pain and cartilage loss in knee osteoarthritis. Ann Rheum Dis. 2007;66:1599-1603.

9. Felson DT, Lawrence RC, Hochberg MC, et al. Osteoarthritis—new insights, part 2: treatment approaches. Ann Intern Med. 2000;133:726-737.

10. Staud R. Evidence for shared pain mechanisms in osteoarthritis, low back pain, and fibromyalgia. Curr Rheumatol Rep. 2011; 13:513-520.

11. Mease PJ, Hanna S, Frakes EP, Altman RD. Pain mechanisms in osteoarthritis: understanding the role of central pain and current approaches to its treatment. J Rheumatol. 2011;38:1546-1551. 
12. Sofat N, Ejindu V, Kiely P. What makes osteoarthritis painful: the evidence for local and central pain processing. Rheumatology (Oxford). 2011;50:2157-2165.

13. Lee YC, Nassikas NJ, Clauw DJ. The role of the central nervous system in the generation and maintenance of chronic pain in rheumatoid arthritis, osteoarthritis and fibromyalgia. Arthritis Res Ther. 2011; 13:211.

14. Murphy SL, Phillips K, Williams DA, Clauw DJ. The role of the central nervous system in osteoarthritis pain and implications for rehabilitation. Curr Rheumatol Rep. 2012;14:576-582.

15. Lluch Girbés E, Nijs J, Torres-Cueco R, López Cubas C. Pain treatment for patients with osteoarthritis and central sensitization. Phys Ther. 2013 Jun;93(6):842-51. doi: 10.2522/ptj.20120253. Epub 2013 Feb 7. PMID: 23392185.

16. Fregni F, Gimenes R, Valle AC, Ferreira MJ, Rocha RR, Natalle L, et al. A randomized, sham-controlled, proof of principle study of transcranial direct current stimulation for the treatment of pain in fibromyalgia. Arthritis Rheum 2006;54(12):3988e98.

17. Simis M, Reidler JS, Duarte Macea D, Moreno Duarte I, Wang X, Lenkinski R, et al. Investigation of central nervous system dysfunction in chronic pelvic pain using magnetic resonance spectroscopy and noninvasive brain stimulation. Pain Prac 2014;15(5):423e32.

18. Mori F, Codeca C, Kusayanagi H, Monteleone F, Buttari F, Fiore S, et al. Effects of anodal transcranial direct current stimulation on chronic neuropathic pain in patients with multiple sclerosis. J Pain 2010;11(5):436e42.

19. Antal A, Terney D, Kuhnl S, Paulus W. Anodal transcranial direct current stimulation of the motor cortex ameliorates chronic pain and reduces short intracortical inhibition. J Pain Symptom Manage 2010;39(5):890e903.

20. Lefaucheur JP. The use of repetitive transcranial magnetic stimulation (rTMS) in chronic neuropathic pain. Neurophysiol Clin 2006;36:117-24.

21. Nguyen JP, Nizard J, Keravel Y, Lefaucheur JP. Invasive brain stimulation for the treatment of neuropathic pain. Nat Rev Neurol 2011;7:699-709.

22. Nitsche MA, Paulus W. Sustained excitability elevations induced by transcranial DC motor cortex stimulation in humans. Neurology 2001;57:1899-901. 
23. Nitsche MA, Seeber A, Frommann K, Klein CC, Rochford C, Nitsche MS, Fricke K, Liebetanz D, Lang N, Antal A, Paulus W, Tergau F. Modulating parameters of excitability during and after transcranial direct current stimulation of the human motor cortex. J Physiol. 2005 Oct 1;568(Pt 1):291-303. doi: 10.1113/jphysiol.2005.092429. Epub 2005 Jul 7. PMID: 16002441; PMCID: PMC1474757.

24. Ohn SH, Park CI, Yoo WK, Ko MH, Choi KP, Kim GM, Lee YT, Kim YH. Time-dependent effect of transcranial direct current stimulation on the enhancement of working memory. Neuroreport. 2008 Jan 8;19(1):43-7. doi: 10.1097/WNR.0b013e3282f2adfd. PMID: 18281890.

25. C.J. Stagg, G. Jayaram, D. Pastor, Z.T. Kincses, P.M. Matthews, H. Johansen-Berg. Polarity and timingdependent effects of transcranial direct current stimulation in explicit motor learning. Neuropsychologia. 2011

Apr; 49(5):

$800-$

804. doi: 10.1016/j.neuropsychologia.2011.02.009 PMCID: PMC3083512

26. Pollonini, L., Miao, H., \& Ahn, H. (2020). Longitudinal effect of transcranial direct current stimulation on knee osteoarthritis patients measured by functional infrared spectroscopy: a pilot study. Neurophotonics, 7(2), 025004. https://doi.org/10.1117/1.NPh.7.2.025004

27. Altman R, Asch E, Bloch D, Bole G, Borenstein D, Brandt K, et al. Development of criteria for the classification and reporting of osteoarthritis: classification of osteoarthritis of the knee. Arthritis Rheum 1986;29:1039-49.--

28. Hawker GA, Mian S, Kendzerska T, French M. Measures of adult pain: Visual Analog Scale for Pain (VAS Pain), Numeric Rating Scale for Pain (NRS Pain), McGill Pain Questionnaire (MPQ), Short-Form McGill Pain Questionnaire (SF-MPQ), Chronic Pain Grade Scale (CPGS), Short Form-36 Bodily Pain Scale (SF36 BPS), and Measure of Intermittent and Constant Osteoarthritis Pain (ICOAP). Arthritis Care Res (Hoboken) 2011; 63(S11):S240-S252. https://doi.org/10.1002/acr.20543

29. Tubach F, Ravaud P, Baron G, et al. Evaluation of clinically relevant changes in patient reported outcomes in knee and hip osteoarthritis: the minimal clinically important improvement. Ann Rheum Dis 2005; 64(1):29-33. https://dx.doi.org/10.1136\%2Fard.2004.022905

30. Ateef M, Kulandaivelan S, Tahseen S. Test-retest reliability and correlates of 6-minute walk test in patients with primary osteoarthritis of knees. Indian J Rheumatol, 2016;11:192-96. Doi: 10.4103/0973-3698.192668 
31. Doganay B, Erdogan BD, Leung YY, Pohl C, Tennant A, Conaghan PG. Minimal clinically important difference as applied in Rheumatology: An OMERACT Rasch working group systematic review and critique. J Rheumatol 2016; 43(1):194-202. https://doi.org/10.3899/jrheum.141150

32. Lee AL, Hill CJ, Cecins N, et al. Minimal important difference in field tests of non-cystic bronchiectasis $\begin{array}{lllll}\text { following } & \text { exercise } & \text { training. } & \text { Respir } & \text { Med }\end{array}$ 1309. https://doi.org/10.1016/j.rmed.2014.07.006

33. Bohannon RW, Crouch R. Minimal clinically important difference for change in 6-minute walk test distance of adults with pathology: A systematic review. J Eval Clin Pract 2017; 23(2):377381. https://doi.org/10.1111/jep.12629

34. Ateef M, Kulandaivelan S, Alqahtani M. Cross-cultural validation of Urdu version KOOS in Indian population with primary knee osteoarthritis. Int J Rheumatol 2017:1206706. https://doi.org/10.1155/2017/1206706

35. Ingelsrud LH, Terwee CB, Terluin B, et al. Meaningful Change Scores in the Knee Injury and Osteoarthritis Outcome Score in Patients Undergoing Anterior Cruciate Ligament Reconstruction. Am J Sports Med. 2018;46(5):1120-1128. doi:10.1177/0363546518759543

36. Schabrun SM, Jones E, Elgueta Cancino EL, Hodges PW .Targeting chronic recurrent low back pain from the top-down and the bottom-up: a combined transcranial direct current stimulation and peripheral electrical stimulation intervention. Brain Stimul. 2014 May-Jun;7(3):451-9. doi: 10.1016/j.brs.2014.01.058. Epub 2014 Jan 30.

37. Boggio PS, Amancio EJ, Correa CF, Cecilio S, Valasek C, Bajwa Z, et al. Transcranial DC stimulation coupled with TENS for the treatment of chronic pain: a preliminary study. Clin J Pain 2009;25:691-5.

38. Hazime FA, de Freitas DG, Monteiro RL, et al. Analgesic efficacy of cerebral and peripheral electrical stimulation in chronic nonspecific low back pain: a randomized, double-blind, factorial clinical trial. BMC Musculoskelet Disord. 2015;16(1):7. Published 2015 Jan 31. doi:10.1186/s12891-015-0461-1

39. Jafarzadeh A, Ehsani F, Yosephi MH, Zoghi M, Jaberzadeh S. Concurrent postural training and M1 anodal transcranial direct current stimulation improve postural impairment in patients with chronic low back pain. J Clin Neurosci. 2019 Oct; 68:224-234. Doi: 10.1016/j.jocn.2019.07.017. 
40. Luedtke K, ,Rushton A,Wright C, Jürgens T, Polzer A,Mueller G, May A. Effectiveness of transcranial direct current stimulation preceding cognitive behavioural management for chronic low back pain: sham controlled double blinded randomised controlled trial. BMJ 2015;350:h1640. doi: https://doi.org/10.1136/bmj.h1640.

41. Straudi S, Buja S, Baroni A, Pavarelli C, Pranovi G, Fregni F, Basaglia N.The effects of transcranial direct current stimulation (tDCS) combined with group exercise treatment in subjects with chronic low back pain: a pilot randomized control trial. Clin Rehabil. 2018 Oct;32(10):1348-1356. doi: 10.1177/0269215518777881. Epub 2018 May 21.

42. Chang WJ, Bennell KL, Hodges PW, et al. Addition of transcranial direct current stimulation to quadriceps strengthening exercise in knee osteoarthritis: A pilot randomised controlled trial. PLoS One. 2017;12(6):e0180328. doi:10.1371/journal.pone.0180328

43. Ahn $\mathrm{H}$, Zhong $\mathrm{C}$, Miao $\mathrm{H}$, et al. Efficacy of combining home-based transcranial direct current stimulation with mindfulness-based meditation for pain in older adults with knee osteoarthritis: A randomized controlled pilot study. J ClinNeurosci. 2019;70:140-145. doi:10.1016/j.jocn.2019.08.047

44. Ahn H, Woods AJ, Kunik ME, et al. Efficacy of transcranial direct current stimulation over primary motor cortex (anode) and contralateral supraorbital area (cathode) on clinical pain severity and mobility performance in persons with knee osteoarthritis: An experimenter- and participant-blinded, randomized, sham-controlled pilot clinical study. Brain Stimul. 2017;10(5):902-909. doi:10.1016/j.brs.2017.05.007

Table 1 showing the value of mean and SD, within group and between group comparison of the subjects

\begin{tabular}{|r|l|l|l|l|}
\hline S. No & Outcome Variables & Mean and SD & $\begin{array}{l}\text { Within subjects effects } \\
\text { F, P value and Effect } \\
\text { size }\end{array}$ & $\begin{array}{l}\text { Between subjects } \\
\text { effects } \\
\text { F, P value and } \\
\text { Effect size }\end{array}$ \\
& & & & \\
& & & & \\
\hline 1. & VAS_Baseline & & & \\
\hline 2. & VAS_Day 1 Pre & $6.06 \pm .82$ & $268.206, \mathrm{p}=.000^{*}, \mathrm{ES}=$ & $733.194, \quad \mathrm{p}=.000^{*}$, \\
\hline 3. & VAS_Week 1 & $5.21 \pm .73$ & .944 & \\
\hline 4. & VAS_Week 2 & $2.91 \pm .95$ & & \\
\hline 5. & VAS_Week 6 & $2.55 \pm .84$ & & \\
\hline
\end{tabular}




\begin{tabular}{|c|c|c|c|c|c|}
\hline 6. & 6 MWT_Baseline & $338.65 \pm 59.20$ & \multirow{4}{*}{$\begin{array}{l}\text { 44.611, } \\
E S=.736\end{array}$} & \multirow[t]{4}{*}{$\mathrm{p}=.000^{*}$} & \multirow{4}{*}{$\begin{array}{ll}666.81, & \mathrm{p}=.000 * \\
\mathrm{ES}=.977 & \end{array}$} \\
\hline 7. & 6 MWT_Week 1 & $352.82 \pm 58.32$ & & & \\
\hline 8. & 6 MWT_Week 2 & $360.41 \pm 56.98$ & & & \\
\hline 9. & 6 MWT_Week 6 & $366.59 \pm 54.83$ & & & \\
\hline 10. & KOOS_Sym_Baseline & $40.88 \pm 6.48$ & \multirow{4}{*}{$\begin{array}{l}160.67 \\
E S=.909\end{array}$} & \multirow[t]{4}{*}{$\mathrm{p}=.000^{*}$} & \multirow{4}{*}{$\begin{array}{l}\text { 2033.55, } \mathrm{p}=.000^{*}, \mathrm{ES} \\
.992\end{array}$} \\
\hline 11. & KOOS_Sym_W1 & $52.00 \pm 8.46$ & & & \\
\hline 12. & KOOS_Sym_W 2 & $61.59 \pm 6.09$ & & & \\
\hline 13. & KOOS_Sym_W6 & $70.59 \pm 7.97$ & & & \\
\hline 14. & KOOS_Pain_Baseline & $44.76 \pm 8.48$ & \multirow{4}{*}{$\begin{array}{l}54.26, \\
\mathrm{ES}=.772\end{array}$} & \multirow[t]{4}{*}{$\mathrm{p}=.000^{*}$} & \multirow{4}{*}{$\begin{array}{l}1364.229 \\
\mathrm{ES}=.988\end{array}$} \\
\hline 15. & KOOS_Pain_Week 1 & $53.59 \pm 7.78$ & & & \\
\hline 16. & KOOS_Pain_Week 2 & $61.82 \pm 10.78$ & & & \\
\hline 17. & KOOS_Pain_Week 6 & $68.41 \pm 9.53$ & & & \\
\hline 18. & KOOS_Func_Baseline & $40.59 \pm 8.00$ & \multirow{4}{*}{$\begin{array}{l}\text { 105.48, } \\
\mathrm{ES}=.868\end{array}$} & \multirow[t]{4}{*}{$\mathrm{p}=.000^{*}$} & \multirow{4}{*}{$\begin{array}{l}1986.43 \\
\mathrm{ES}=.992\end{array}$} \\
\hline 19. & KOOS_Func_Week1 & $52.00 \pm 7.02$ & & & \\
\hline 20. & KOOS_Func_Week 2 & $61.06 \pm 5.90$ & & & \\
\hline 21. & KOOS_Func_Week 6 & $70.29 \pm 8.96$ & & & \\
\hline 22. & KOOS_SF_Baseline & $17.94 \pm 7.81$ & \multirow{4}{*}{$\begin{array}{l}43.32 \\
E S=.730\end{array}$} & \multirow[t]{4}{*}{$\mathrm{p}=.000^{*}$, } & \multirow{4}{*}{$\begin{array}{l}169.747 \\
E S=.914\end{array}$} \\
\hline 23. & KOOS_SF_Week 1 & $24.00 \pm 8.54$ & & & \\
\hline 24. & KOOS_SF_Week 2 & $29.24 \pm 10.65$ & & & \\
\hline 25. & KOOS_SF_Week 6 & $35.59 \pm 11.30$ & & & \\
\hline 26. & KOOS_QoL_Baseline & $33.88 \pm 5.56$ & \multirow{4}{*}{$\begin{array}{l}\text { 137.998, } \\
E S=.896\end{array}$} & \multirow[t]{4}{*}{$\mathrm{p}=.000^{*}$} & \multirow{4}{*}{$\begin{array}{l}2068.08, \quad p=.000^{*}, \\
E S=.992\end{array}$} \\
\hline 27. & KOOS_QoL_Week 1 & $39.24 \pm 5.49$ & & & \\
\hline 28. & KOOS_QoL_Week 2 & $46.24 \pm 4.32$ & & & \\
\hline 29. & KOOS_QoL_Week 6 & $53.66 \pm 5.11$ & & & \\
\hline
\end{tabular}

Significance at $\mathrm{p}<0.001^{*}$

Table 2 showing the pairwise comparison and the value of mean difference and $95 \% \mathrm{CI}$ and $\mathrm{P}$ value for the outcome variables

\begin{tabular}{|r|l|l|l|l|}
\hline S. No & Outcome Variables & MD & $\mathbf{9 5}$ \% CI & P value \\
\hline 1. & VAS_Immediate & $.847^{*}$ & $.431,1.264$ & .000 \\
\hline 2. & VAS_Week 1 & $3.14^{*}$ & $2.16,4.12$ & .000 \\
\hline 3. & VAS_Week 2 & $3.51^{*}$ & $2.64,4.38$ & .000 \\
\hline 4. & VAS_Week 6 & $4.08^{*}$ & $3.30,4.86$ & .000 \\
\hline 5. & 6 MWT_Week 1 & -14.17 & $-28.80, .451$ & $.061(\mathrm{NS})$ \\
\hline 6. & 6 MWT_Week 2 & $-21.76^{*}$ & $-36.21,-7.31$ & .002 \\
\hline 7. & 6 MWT_Week 6 & -27.94 & $-41.11,-14.76$ & .000 \\
\hline 8. & KOOS_Sym_W1 & $-11.11^{*}$ & $-13.72,-8.50$ & .000 \\
\hline 9. & KOOS_Sym_W 2 & -20.70 & $-24.33,-17.07$ & .000 \\
\hline 10. & KOOS_Sym_W6 & -29.70 & $-34.62,-24.79$ & .000 \\
\hline 11. & KOOS_Pain_Week 1 & $-8.82^{*}$ & $-13.74,-3.89$ & .002 \\
\hline 12. & KOOS_Pain_Week 2 & $-17.02^{*}$ & $-23.02,-11.09$ & .000 \\
\hline 13. & KOOS_Pain_Week 6 & $-23.64^{*}$ & $-31.05,-16.23$ & .000 \\
\hline 14. & KOOS_Func_Week1 & $-11.41^{*}$ & $-14.75,-8.06$ & .000 \\
\hline 15. & KOOS_Func_Week 2 & $-20.47^{*}$ & $-24.86,-16.08$ & .000 \\
\hline 16. & KOOS_Func_Week 6 & $-29.70^{*}$ & $-35.64,-23.76$ & .000 \\
\hline 17. & KOOS_SF_Week1 & $-6.05^{*}$ & $-8.73,-3.38$ & .000 \\
\hline 18. & KOOS_SF_Week 2 & $-11.29^{*}$ & $-15.87,-6.71$ & .000 \\
\hline 19. & KOOS_SF_Week 6 & $-17.64^{*}$ & $-23.19,-12.10$ & .000 \\
\hline 20. & KOOS_QoL_Week 1 & $-5.35^{*}$ & $-7.29,-3.41$ & .000 \\
\hline 21. & KOOS_QoL_Week 2 & $-12.35^{*}$ & $-15.54,-9.16$ & .000 \\
\hline 22. & KOOS_QoL_Week 6 & $-23.41^{*}$ & $-23.41,-16.58$ & .000 \\
\hline
\end{tabular}

Significance level $\mathrm{P}<0.001 *$ 
